\title{
Intraspecies Interaction of Fusarium graminearum Contributes to Reduced Toxin Production and Virulence
}

\author{
Sean Walkowiak, ${ }^{1,2}$ Christopher T. Bonner, ${ }^{1,2}$ Li Wang, ${ }^{1}$ Barbara Blackwell,, ${ }^{1}$ Owen Rowland, ${ }^{2}$ and \\ Rajagopal Subramaniam ${ }^{1}$ \\ ${ }^{1}$ Eastern Cereal and Oilseed Research Centre, 960 Carling, Agriculture and Agri-Food Canada, Ottawa K1A 0C6, Canada; \\ ${ }^{2}$ Department of Biology, 1125 Colonel By, Carleton University, Ottawa K1S 5B6, Canada
}

Submitted 3 June 2015. Accepted 26 June 2015.

\begin{abstract}
Fusarium graminearum is a pathogenic fungus that causes Fusarium head blight in wheat and lowers the yield and quality of grains by contamination with the trichothecene mycotoxin deoxynivalenol. The fungi coexist and interact with several different fusaria as well as other plant pathogenic fungi and bacteria in the field. In Canada, $F$. graminearum exists as two main trichothecene chemotypes: 3-acetyldeoxynivalenol and 15-acetyldeoxynivalenol. To understand the potential interactions between two isolates of these chemotypes, we conducted coinoculation studies both in culture and in planta. The studies showed that intraspecies interaction reduces trichothecene yield in culture and disease symptoms in wheat. To elucidate the genes involved in the intraspecies interaction, expression profiling was performed on RNA samples isolated from coinoculated cultures, and potential genes were identified by using the genome sequences of the respective isolates.
\end{abstract}

The Fusarium sambucinum species complex is composed of several distinct fungal species that are attributed with a number of plant diseases in cereals, including Fusarium head blight (FHB) of wheat and barley and Gibberella ear rot of corn (Boutigny et al. 2011; Geiser et al. 2013). These pathogens have a broad global distribution and have been identified in Asia, Africa, Australia, Europe, and the Americas (McMullen et al. 1997). As part of the infection process, members of the species complex produce an array of trichothecene mycotoxins, including deoxynivalenol (DON); these toxins contaminate the host plant and make it unfit for consumption. Economic losses caused by reduced yields and contamination by mycotoxins are severe (McMullen et al. 1997; Windels 2000).

Although individuals within the $F$. sambucinum species complex, such as $F$. graminearum, can cause similar disease symptoms in planta, isolates have distinct physical, physiological, behavioral, and molecular profiles (Doohan et al. 1998; Geiser et al. 2013; O'Donnell et al. 2004; Wagacha et al. 2012). Fusarium isolates obtained from various plant hosts from around

Corresponding author: Rajagopal Subramaniam; Telephone: +1.613.759.7619; E-mail: rajagopal.subramaniam@agr.gc.ca

Genome assemblies for FG1 and FG2 have been deposited in the National Center for Biotechnology Information (NCBI) catabase under accession numbers GCA_000966635.1 and GCA_000966645.1.

*The $\boldsymbol{e}$-Xtra logo stands for "electronic extra" and indicates that five supplementary figures and seven supplementary tables are published online.

(C) Her Majesty the Queen in Right of Canada, as represented by the Minister of Agriculture and Agri-Food Canada, 2015. the world have different toxin and pathogenicity profiles in wheat, with some isolates being completely nonpathogenic (Bai and Shaner 1996; O'Donnell et al. 2000). A survey of Fusarium disease in South Africa and another independent survey in Korea suggest that different species coexist in the same geographic regions and are better adapted to cause infection within specific hosts (Boutigny et al. 2011; Lee et al. 2009). It has also been suggested that different fusaria interact, either directly or indirectly, with each other and other microbes in the field; these interactions can be antagonistic or synergistic (Doohan et al. 1998; Xu et al. 2005). Interspecies interactions between fusaria in vitro have been demonstrated to affect germination and germtube growth; species also have zones of inhibition between them, indicating individuals can detect and respond to each other (Wagacha et al. 2012). Field trials with F. graminearum and F. culmorum isolates, inoculated either individually or together, suggested that isolates can outcompete one another and the competition outcome was dependent on various environmental factors (Von der Ohe and Miedaner 2011). The importance of environment is underscored by another coinoculation study, in which coinoculation with $F$. graminearum and $F$. verticillioides resulted in either increased or decreased abundance of a single species, depending on the field conditions (Picot et al. 2012). Interestingly, the authors also reported natural contamination from other Fusarium spp., thus underscoring the complex interactions that exist between multiple microbes in the field (Picot et al. 2012). Although numerous studies showed fusaria coexist within similar geographic areas and likely interact with each other and other microbes, little is known about direct intraspecies interactions.

In Canada, FHB is predominantly caused by the species F. graminearum. Genetic markers identified two dominant genetic populations of $F$. graminearum in North America that are largely associated with two trichothecene chemotypes, 3acetyldeoxynivalenol (3-ADON) or 15-ADON (Liang et al. 2014). These two chemotypes also dominate Canadian farms and the differences in toxin type are attributed to allele differences in the biosynthetic gene Tri8 (Alexander et al. 2011). A study suggested that $3-\mathrm{ADON}$ isolates are more toxigenic and have increased growth capacity than the $15-\mathrm{ADON}$-producing isolates (Ward et al. 2008). The same study also indicated that the distribution and prevalence of these chemotypes across the country differ and are likely dynamic, with $3-\mathrm{ADON}$-producing isolates potentially displacing the 15-ADON chemotypes (Ward et al. 2008). Chemotype success has been shown to be variable and linked to several different factors, such as temperature and wheat cultivars (Foroud et al. 2012; Gilbert et al. 2014). This suggests that genetic factors other than chemotype differences might contribute to the success of a particular isolate. 
We sought to investigate interactions between 3-ADON (FG1) and 15-ADON (FG2) $F$. graminearum isolates at the molecular level. The two isolates were assessed for their toxin production in culture and pathogenicity in wheat, independently and in combination. The data suggested that the two isolates are capable of producing toxins and are virulent; however, in combination, both trichothecene production and disease symptoms were reduced. Analyses of the two genomes showed significant similarity but, also, revealed genes that are poorly conserved or distinct to each isolate. RNA sequencing identified genes that behaved differently between isolates and genes responsive to intraspecies interaction.

\section{RESULTS}

Interference between $\boldsymbol{F}$. graminearum isolates affects trichothecene production in vitro.

In Canada, FHB is primarily caused by the species $F$. graminearum and the dominant chemotypes produce either the 3- or 15-ADON trichothecene (Ward et al. 2008). Since these chemotypes coexist in the same geographic regions, we sought to dissect possible interactions between an isolate of each chemotype. To assess direct interactions between isolates affecting toxin production, we used a modified two-stage media method to induce trichothecene production.

Toxin type for each isolate was determined by high-performance liquid chromatography (HPLC) and nuclear magnetic resonance (NMR). HPLC was able to resolve 3-ADON in the FG1 culture supernatant at approximately $13.5 \mathrm{~min}$ and $15-\mathrm{ADON}$ at approximately $15 \mathrm{~min}$ in the FG2 culture supernatant (Supplementary Fig. S1). NMR analysis of the ethyl acetate extracts of the culture filtrates from the two isolates also showed the presence of 3-ADON for FG1 and 15-ADON for FG2 (Savard and Blackwell 1994) (Supplementary Fig. S2). Specifically, the two isomers can be distinguished by the downfield shifts of the protons at the acetylated positions, H-3 and H-15. In addition, NMR analysis also detected the sesquiterpene culmorin and the modified trichothecene sambucinol for both isolates.

Prior to investigating if interactions between FG1 and FG2 affect trichothecene production, we assessed whether or not reducing the starting inoculum affected mycotoxin production. The results indicated that starting the inoculum at 5,000 spores per milliliter and progressively diluting the inoculum to 90,50 , and $10 \%$ with water did not significantly affect the production of either mycotoxin (Fig. 1A and B, gray and white bars, respectively). Moreover, regardless of the amount of starting inoculum, FG1 consistently produced half of the amount of ADON compared with FG2 (Fig. 1A and B, gray and white bars, respectively). To determine if either of the isolates influenced mycotoxin production in the other, we quantified ADONs in FG1 and FG2 axenic cultures and compared with coinoculated cultures in ratios of $10: 1,1: 1$, and $1: 10$, while maintaining the total concentration of spores at 5,000 spores/ml. FG1 axenic culture produced $285 \mu \mathrm{g}$ of 3-ADON (Fig. 1A, FG1) but only produced $121 \mu \mathrm{g}$ of 3-ADON when it was coinoculated with FG2 in a 10:1 FG1/FG2 ratio (Fig. $1 \mathrm{~A}$, striped bars) and $11 \mu \mathrm{g}$ of $3-\mathrm{ADON}$ when the culture was coinoculated with an equal amount (1:1) of the FG2 isolate (Fig. $1 \mathrm{~A}$, striped bars). In cultures in which the FG2 isolate dominated, we could not detect any 3-ADON from FG1 (Fig. 1A, striped bars, 1:10). We also quantified 15-ADON from FG2 axenic culture and compared it to coinoculated cultures. FG2 axenic culture produced $665 \mu \mathrm{g}$ of toxin (Fig. 1B, FG2), $528 \mu \mathrm{g}$ of toxin when the culture was coinoculated with FG1 isolate in a ratio of 10:1 of FG2:FG1 (Fig. 1B, striped bars), and $370 \mu \mathrm{g}$ of toxin when the culture was coinoculated with equal amount (1:1) of the FG1 (Fig. 1B, striped bars). In cultures in which the FG1 isolate dominated, we detected $132 \mu \mathrm{g}$ of 15-ADON (Fig. 1B, striped bars, 1:10). A quantitative
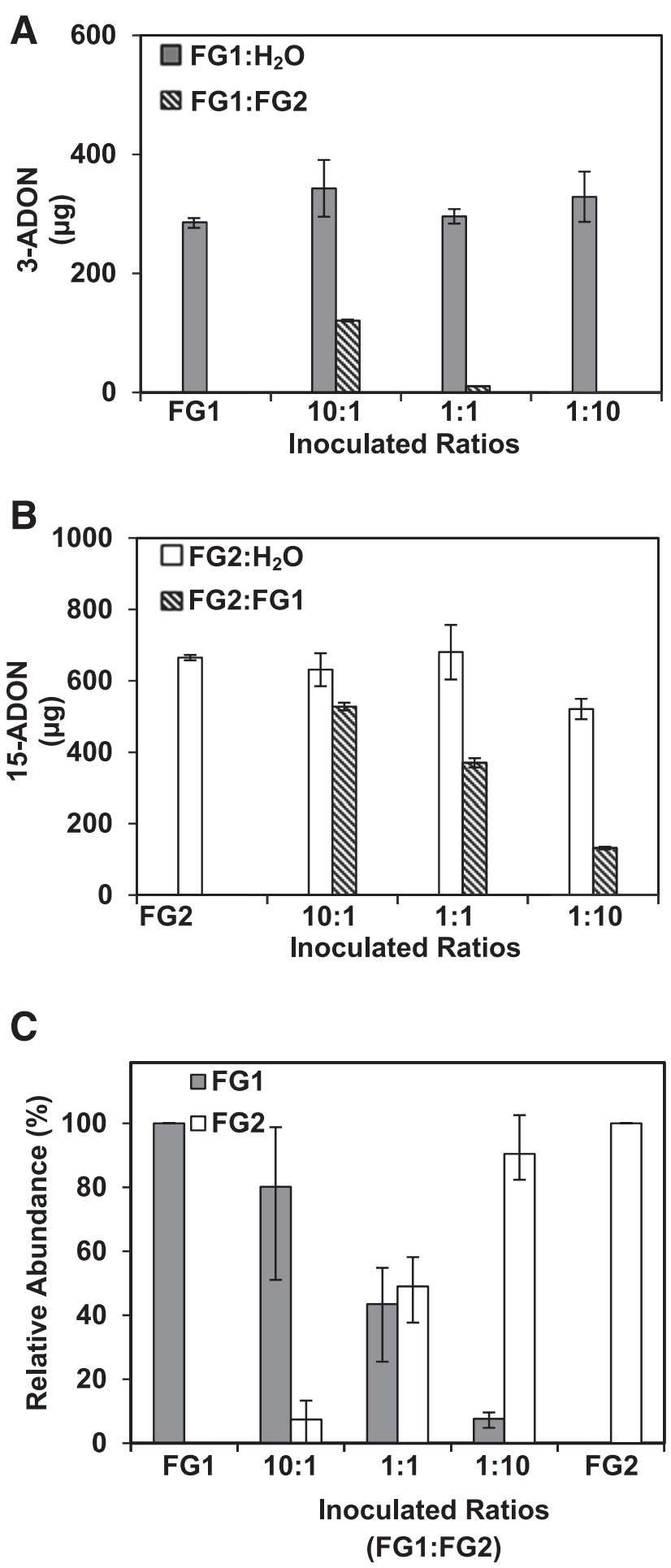

Fig. 1. Coinoculation of Fusarium graminearum isolates reduces trichothecene production in vitro. A, Quantification of 3-acetyldeoxynivalenol (3-ADON) toxin accumulation by high-performance liquid chromatography (HPLC) resulting from dilutions of FG1 with distilled (d) $\mathrm{H}_{2} \mathrm{O}$ (gray) and with FG2 (striped), in a ratio of 10:1, 1:1, and 1:10, respectively. B, Quantification of 15-ADON toxin accumulation by HPLC resulting from dilutions of FG2 with $\mathrm{dH}_{2} \mathrm{O}$ (white) and with FG1 (striped) in ratios of 10:1, $1: 1$, and $1: 10$, respectively. Results are the average yield from 4-ml cultures for three independent samples; errors bars reflect standard error. $\mathbf{C}$, Relative abundance of each isolate is maintained in culture during trichothecene production. Isolates were either inoculated alone or in a ratio of 10:1, 1:1, or 1:10 (FG1:FG2). The relative abundance of FG1 (gray) and FG2 (white) was determined independently, using quantitative real-time polymerase chain reaction primers specific to each single isolate. Results represent the average of five independent samples tested in triplicate; error bars reflect the maximum and minimum across the five independent samples. 
real-time polymerase chain reaction (qRT-PCR) analysis was used to verify relative abundance of each isolate in the culture. A gene marker unique to each isolate ( $g 6419$ for FG1 and $g 6823$ for FG2) showed that the abundance is similar to that of the initial inoculum, which suggested that the reduction in toxin production is not caused by an isolate competitively excluding growth of the other (Fig. 1C).

To further rule out the possibility that coinoculation was influencing growth rates, we determined the growth rate of each

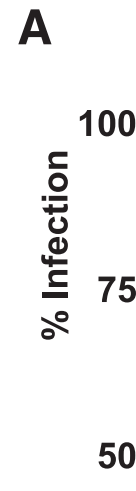

B

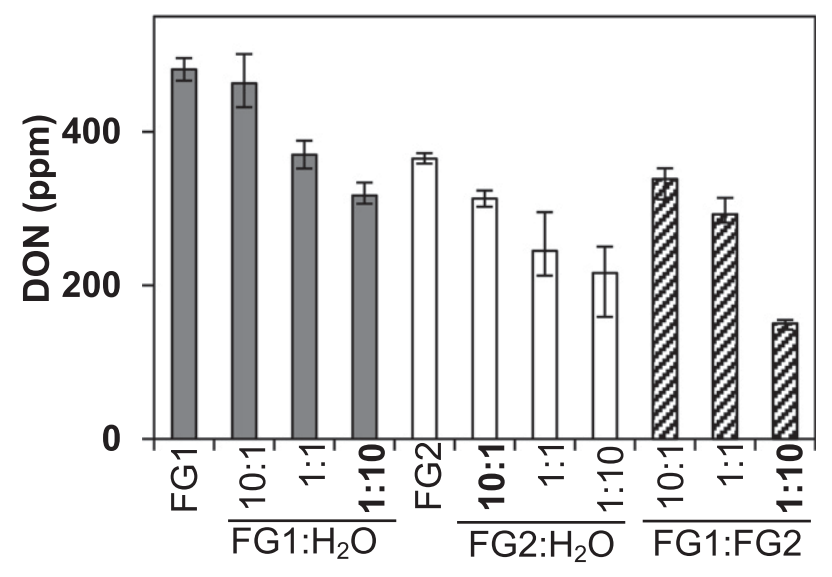

Inoculated Ratios

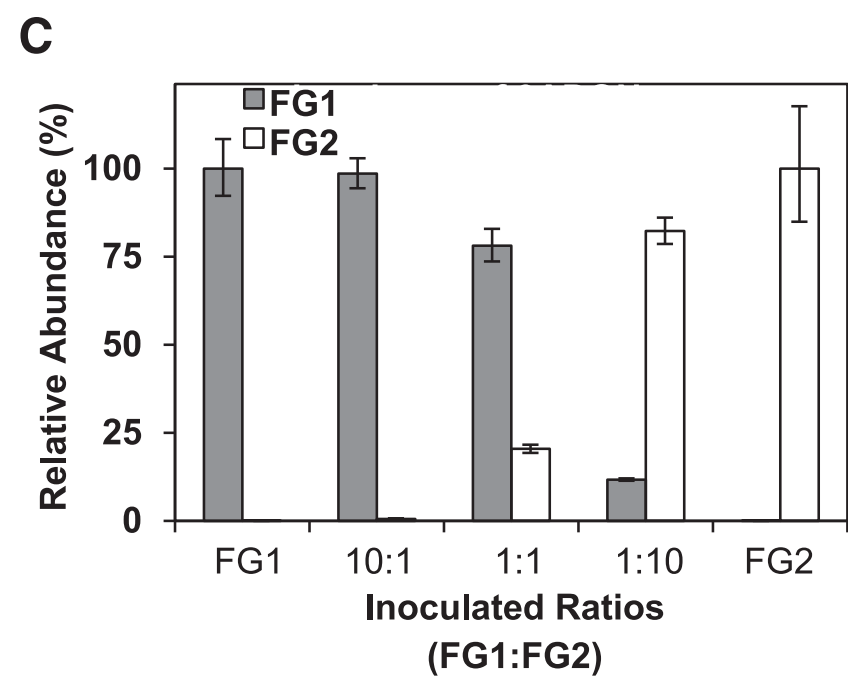

isolate alone or in different ratios in both nutrient-limiting minimal medium and in nutrient-rich potato dextrose medium by optical density in liquid and by radial growth on solid medium (Supplementary Fig. S3). Both isolates had similar growth rates in the nutrient-limiting minimal media, regardless if they were grown in liquid or solid media. We observed differences in growth between isolates on the solid nutrient-rich potato dextrose medium. After 4 days, FG1 increased (approximately $1.5 \mathrm{~cm}$ ) radial growth on the solid medium compared with FG2. In contrast, no differences were observed between the two isolates in the liquid potato dextrose medium. We also observed no significant changes in growth in either media condition when isolates were coinoculated.

\section{Interference between $\boldsymbol{F}$. graminearum isolates affects disease outcome in planta.}

To determine if the decrease in toxin production of the two isolates in coinoculated conditions influenced disease outcome, we point-inoculated spores of the two isolates, either alone or in combination, on susceptible wheat cultivar Roblin and assessed disease symptoms and quantified DON in the infected wheat heads. After 21 days postinoculation (dpi), point-inoculation of either isolate alone caused disease symptoms, with FG1 causing slightly more disease symptoms (96\% infection) than FG2 (83\% infection), $P<0.01$ (Fig. 2A). We observed a direct relationship between increased disease symptoms and DON accumulation (481 parts per million [ppm] in FG1 and 365 ppm in FG2 [Fig. 2B]). Diluting the spores of either isolate with water in a ratio of 10:1, 1: 1 , or $1: 10$, thereby decreasing the inoculum from approximately 1,000 spores to approximately 900,500 , or 100 spores, respectively, did not cause a statistically significant difference in the amount of disease symptoms for either isolate (Fig. 2A); however, when the inoculum was reduced, there was a reduction in the amount of DON that accumulated in the wheat heads $(481 \mathrm{ppm}$ for 1,000 spores of FG1 to $317 \mathrm{ppm}$ for 100 spores; and $365 \mathrm{ppm}$ for 1,000 spores of FG2 to 216 ppm for 100 spores [Fig. 2B]).

Next, we performed a coinoculation experiment while maintaining the total spore inoculum at 1,000. As results indicate, coinoculation with FG1 to FG2 in the ratio of $1: 1$ and 10:1 resulted in 88 and $92 \%$ infection, respectively (Fig. 2A), both

Fig. 2. Coinoculation of Fusarium graminearum isolates affects disease outcomes in wheat. A, Wheat heads were point-inoculated with spores from FG1 $(n=107)$ and FG2 isolates $(n=106)$, where $n$ represents the number of wheat heads. Inoculations were also performed with spores from the FG1 diluted with water in a ratio of 10:1 $(n=43), 1: 1(n=43)$, and 1:10 $(n=42)$ (gray) (FG1: $\left.\mathrm{H}_{2} \mathrm{O}\right)$. Similarly, spores from the FG2 isolate were inoculated after dilution with water in a ratio of 10:1 $(n=43), 1: 1(n=41)$, and 1:10 $(n=42)$ (white) $\left(\mathrm{FG} 2: \mathrm{H}_{2} \mathrm{O}\right)$. Disease symptoms were also assessed with combinations of spores from FG1 and FG2 in ratios of 10:1 $(n=75), 1: 1$ $(n=76)$, and 1:10 $(n=76)$ (striped) (FG1/FG2). Results are presented as percent spikelets with disease symptoms at 21 days postinoculation (dpi). Error bars reflect standard error, while $a$ and $b$ denote values that are statistically different with a $P$ value of 0.1 or below, compared with sole inoculation of FG1 and FG2 isolates, respectively, by one-tailed Student's $t$ test. A single asterisk (*) represents a significance of $0.05 \geq P$ value $\geq 0.01$, while two asterisks $(* *)$ represents a significance of $P$ value $\leq 0.01$. The $1: 10$ ratio in bold highlights the conditions in which the coinoculated isolates significantly decrease disease outcome compared with each isolate diluted with water in the same ratio. B, A total of 32 wheat heads from each condition were tested for DON content by enzyme-linked immunosorbent assay. The 1:10 ratio in bold highlights the conditions in which there was a decrease in DON accumulation compared with equivalent amounts of the isolates diluted with water. Error bars reflect the maximum and minimum across three independent replicates. $\mathbf{C}$, Relative abundance of each isolate is not maintained in wheat by the end point of infection ( $21 \mathrm{dpi}$ ). The relative abundance of FG1 (gray) and FG2 (white) was determined independently across 32 wheat heads from each condition, using quantitative real-time polymerase chain reaction primers specific to each single isolate. 
less than the sole inoculum of FG1 but greater than a sole inoculum of FG2 (Fig. 2A). Coinoculation of FG1 and FG2 in the ratio of 1:10 resulted in significant reduction in disease symptoms (71\% infection) (Fig. 2A), compared with corresponding dilution of FG1 with water (95\% infection) or FG2 with water (87\% infection), $P<0.05$ (Fig. 2A). The reduction in disease symptoms in this condition was reflected by a reduction in DON accumulation to $150 \mathrm{ppm}$, which is less than half of the equal inoculum of FG1 (317 ppm) or FG2 (313 ppm) (Fig. 2B).

Since we observed differences in virulence during coinoculated conditions, we were also interested to know which Fusarium isolate dominated at the end point of infection, which was assessed by both PCR and qRT-PCR, using isolate-specific markers ( $g 6419$ for FG1 and g6823 for FG2). qRT-PCR was used to detect the relative abundance of the isolates across several wheat heads (Fig. 2C), while PCR allowed us to determine the presence or absence of the isolate in a single wheat head (Supplementary Fig. S4). As expected, when the wheat heads were inoculated alone, only the inoculated isolate was detected (Fig. 2C). When the composition of the inoculum contained equal ratios of the two isolates, the wheat heads were mostly dominated by FG1 at the end of infection (Fig. 2C). When the wheat heads were inoculated with spores dominated by FG1, we only detected FG1 (Fig. 2C). However, when FG2 was the dominant inoculum, we detected both FG2 and FG1 in wheat heads, albeit FG2 was more abundant (Fig. 2C). In several instances, we were also able to detect both isolates in a single wheat head, particularly in the coinoculated conditions in which FG2 dominated the inoculum, which suggested that isolates are interacting throughout the infection process, including at the end point of 21 days.

Collectively, our results suggest that the two isolates infect with different degrees of severity and that combining isolates results in a reduction in disease symptoms. This was particularly evident in the coinoculated conditions, when the FG1 and FG2 isolates were present in a ratio of 1:10. The same ratios also resulted in decreased mycotoxin production in culture (Fig. 1) and in wheat (Fig. 2B), thus emphasizing a link between mycotoxin accumulation and disease spread.

\section{Genome comparisons reveal differences in genome structure and gene content} between 3-ADON- and 15-ADON-producing isolates.

To understand the phenotype differences that we observed both in vitro and in planta, we performed whole genome sequencing of FG1 and FG2 isolates. De novo assembly by CLC Genomics Workbench resulted in a base coverage of $86 x$ and 144x for FG1 and FG2, respectively. Genome assemblies have been deposited in the National Center for Biotechnology Information (NCBI) (accession numbers GCA_000966635.1 and GCA_000966645.1). A summary of genome features is presented along with PH-1 from the Munich Information Center for Protein Sequences (MIPS) database (Table 1) (Wong et al. 2011). All three genomic sequences have a similar size (approximately $37 \mathrm{Mb}$ ) and GC content (48\%) (Table 1).

Table 1. Genome statistics of FG1, FG2, and PH-1 Fusarium graminearum isolates

\begin{tabular}{|c|c|c|c|}
\hline \multirow[b]{2}{*}{ Genome feature } & \multicolumn{3}{|c|}{ F. graminearum isolate } \\
\hline & PH-1 & FG1 & FG2 \\
\hline Method & Sanger & Illumina GAII & Illumina GAII \\
\hline Genome Size (Mb) & 36.6 & 36.6 & 36.5 \\
\hline Coverage (fold) & $10 x$ & $144 \times$ & $86 x$ \\
\hline $\mathrm{N} 50^{\mathrm{a}}(\mathrm{Mb})$ & 5.37 & 0.44 & 0.17 \\
\hline$\% \mathrm{GC}$ & 48 & 48 & 48 \\
\hline
\end{tabular}

a half of the genome length is represented in a contig of this size or greater.
To align the genomes, contig sequences were ordered according to their proposed position in $\mathrm{PH}-1$ using ABACAS prior to alignment by MUMMER (Swain et al. 2012). Alignment of the two genomes and PH-1 showed a high level of sequence conservation between isolates (97 to 98\%) (Table 2). Dotplots of the alignments indicate a high degree of similarity between the three genomes, with a few anomalies in the assemblies, such as poorly aligned or ordered regions (Supplementary Fig. S5). A low coverage sequence $(0.4 \times)$ of the same 15 -ADON isolate, available from NCBI, was also compared with PH-1 and had several regions of poor alignment or could not be ordered to PH-1 and was not used in subsequent analyses. Less than $0.6 \%$ of the aligned nucleotides were single nucleotide polymorphisms (SNPs) or insertions and deletions (indels); these were concentrated at the ends of the chromosomes and select regions within chromosomes (Table 2; Fig. 3). Almost half of the SNPs that were identified were considered high quality SNPs, as they were flanked by regions of nucleotide conservation (Table 2).

In addition to investigating genome structure, we also analyzed the genomes for differences for their gene content by BLASTn and RATT (rapid annotation transfer tool) (Supplementary Table S1) (Otto et al. 2011). A comparison between the PH-1 genome with 13,826 genes (MIPS), and the FG1 and FG2 genomes indicated that 13,376 and 13,440 genes $(>96 \%)$ were conserved and only 134 and 93 were poorly conserved in these two isolates, respectively (Fig. 4). We used AUGUSTUS to predict genes in FG1 and FG2. AUGUSTUS predicted 11,810 genes in FG1, and $>96 \%$, or 11,347 and 11,450 , were conserved in PH-1 and FG2, respectively, while 148 and 147 were poorly conserved (Fig. 4). A similar analysis with the FG2 genome predicted 11,884 genes and also $>96 \%$, or 11,467 and 11,551 , were conserved in PH-1 and FG1, respectively, while 62 and 94 were poorly conserved (Fig. 4). Genes from both isolates that were found to be poorly conserved in PH-1 by BLASTn (E value $>1 \times 10^{-10}$ ) or were not fully transferred to PH-1 by RATT were annotated by Blast-2-GO.

Genes that were poorly conserved by both BLASTn and RATT in the other genomes were considered unique; we identified 55, 121, and 33 genes that met this criteria in PH-1, FG1, and FG2, respectively (Fig. 4; Supplementary Table S2). The unique genes mapped to the regions of high SNP and indel density (Fig. 3). An examination of one region on contig_73 identified nine genes spanning $g 8800$ to $g 8808$ that are unique, and three of these had significant matches to genes from other fusaria by Blast-2-GO. Contig_207 (approximately $90 \mathrm{~kb}$ ) in the FG1 isolate contained 20 predicted genes, 17 of which are poorly conserved in the assembly of both PH1 and FG2 isolates. Interestingly, at least eight of these have been annotated by Blast-2GO to genes similar to genes in other fusaria. Among the other unique genes that were annotated by Blast-2-GO was $g 3560$ in

Table 2. Comparative genomics of FG1, FG2, and PH-1 Fusarium graminearum isolates

\begin{tabular}{llrr}
\hline & & \multicolumn{2}{c}{$\begin{array}{c}\text { F. graminearum } \\
\text { reference genome }\end{array}$} \\
\cline { 3 - 4 } Query genome & \multicolumn{1}{c}{ Alignment statistic } & PH-1 & FG2 \\
\hline FG1 & Aligned bases (\%) & 97 & 97 \\
& Total single nucleotide & 147,555 & 148,979 \\
& polymorphisms (SNPs) & & 64,304 \\
& High quality local SNPs & 64,241 & 63,394 \\
FG2 & Indels & 53,054 & 63,38 \\
& Aligned bases (\%) & 93,774 & - \\
& Total SNPs & 103,859 & - \\
& High quality local SNPs & - \\
& Indels & 45,170 & - \\
\hline
\end{tabular}

${ }^{a}$ A high quality local SNP has at least 20 positively aligned nucleotides adjacent to the SNP on either side. 
contig_207 of FG1, which is predicted to encode for a protease. Other genes on separate contigs include g6520 (contig_192), a predicted salicylate hydroxylase that degrades salicylic acid (SA) to catechol (SA is well-characterized as a signal in plant defense response) (Ding et al. 2011; Makandar et al. 2012) and g2283 (contig_127), which is predicted to encode for a betalactamase that is associated with antibiotic resistance (Allen et al. 2010). Unique genes that were identified in FG2 include a subtilisin-like protease ( $g 6720$, contig_86). Genes associated with heterokaryon incompatibility that may have a role in nonself recognition were also identified as unique in both isolates, which included g6823 (contig_53) in FG2 isolate and g6419 (contig_122) in FG1 isolate (Glass and Kaneko 2003). It is noteworthy that $g 6823$ and $g 6419$ were tagged as unique genetic markers for each isolate and were used in both PCR and qRTPCR analyses (Fig. 1C).

Transcriptome profiling of axenic FG1 and FG2 isolates in mycotoxin-inducing conditions.

While genome analyses revealed common, poorly conserved, and unique genes in each isolate, analysis of activities of these genes may provide more insight into phenotype differences between the isolates. We performed RNA-Seq from axenic cultures grown in the toxin-inducing conditions from five independent biological replicates. Sequence reads were mapped separately to coding sequences of PH-1, FG1, and FG2 isolates using CLC Genomics Workbench. First, we compared the gene expression profiles of axenic cultures directly by DESeq. The profiles revealed that 1,600 to 1,800 or approximately 13 to $15 \%$ of the genes were found to be differentially expressed between FG1 and FG2 by twofold or greater $(P<0.05)$ (Table 3$)$. Functional characterization of the differentially expressed genes using the PH-1 FunCat database revealed an enrichment in genes corresponding to metabolism, energy, and cell rescue, defense, and virulence as well as cell-type differentiation $(P<0.05)$ (Supplementary Table S5).

Many of the differentially expressed genes between the two isolates were associated with secondary metabolism and the production of known Fusarium mycotoxins: 54 were enriched in FG1 and 70 were enriched in FG2. The Tri genes, which are involved in trichothecene production, had greater relative abundance in FG2 than FG1 (Table 4). The expression patterns determined by RNA-Seq were consistent, regardless of which genome was used as reference. Minor variations that were observed between reference genomes, e.g., in Tri8, may be attributed

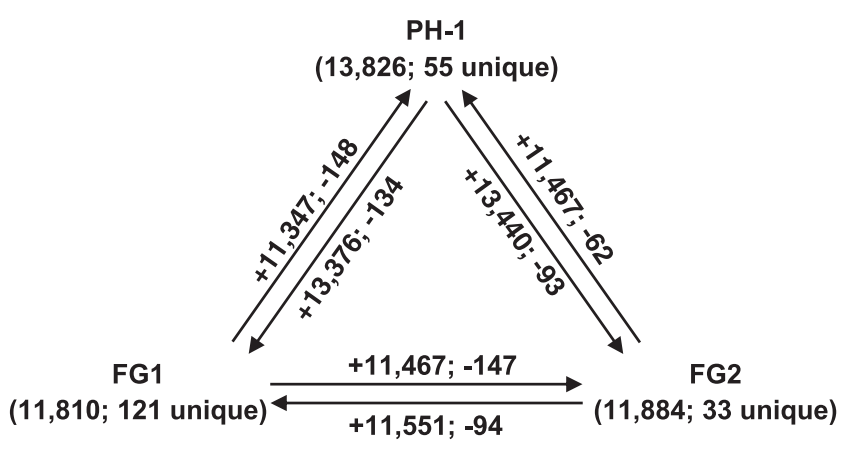

Fig. 4. Gene conservation between Fusarium graminearum isolates. Genes for FG1 and FG2 were predicted by AUGUSTUS and genes from PH-1 were retrieved from the Munich Information Center for Protein Sequences database v. 3.2. Values with a + denote genes that could be successfully transferred by RATT and had a BLASTn expected value less than $1 \times 10^{-10}$, while values with a - represent genes that could not be transferred by RATT and had a BLASTn expected value greater than $1 \times 10^{-10}$. Overlaps of genes in both other genomes were considered unique.
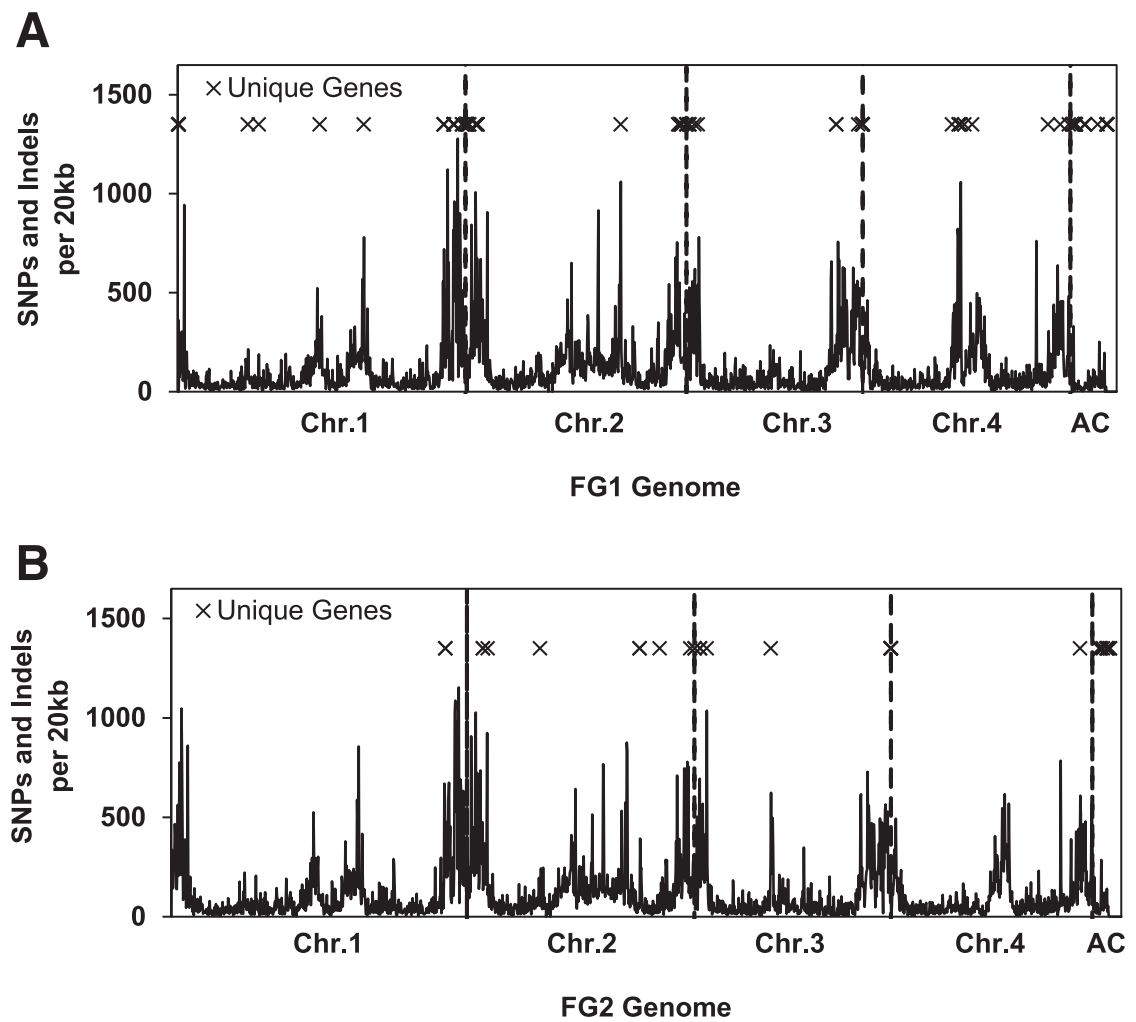

Fig. 3. Unique genes cluster to the regions with high single nucleotide polymorphisms (SNPs) and insertions and deletions (indels) in both FG1 and FG2 genomes. A, Positions of 121 unique genes (crosses) in the FG1 genome with respect to SNPs and indels. The FG1 genome was used as reference. B, Positions of 33 unique genes (crosses) in the FG2 genome with respect to SNPs and indels. The FG2 genome was used as a reference. Genome sequences of FG1 and FG2 genomes were aligned by MUMMER. The four chromosomes as well as additional contigs (AC) are labeled along the $x$ axis. 
to allelic differences between the two isolates (Table 4). Tri8 distinguishes the 3-ADON and 15-ADON chemotypes (Alexander et al. 2011). We verified the RNA-Seq data with qRT-PCR of two genes, Tri6 and Tri5; Tri6 is a positive transcriptional regulator of several genes involved in trichothecene production and transport and Tri5 is the first biosynthetic gene involved in the pathway. The relative quantification of gene expression (RQ) values confirmed that Tri6 had increased expression in FG2 by 4.2-fold, whereas Tri5 was increased in this isolate by 7.9-fold with respect to FG1. Despite the different levels of expression, both isolates are able to make their respective trichothecene product, albeit FG2 produces more than FG1 (Fig. 1). Interestingly, there was incongruity with respect to the expression of the two regulatory genes Tri6 and Tri10; Tril0 is also a positive regulator of genes involved in trichothecene production. Although, Tri6 had increased expression in FG2, similar to other Tri genes and genes of other secondary metabolite clusters, namely, CLM1 (FGSG_10397) of culmorin production and genes spanning FGSG_08077 through FGSG_08084 of the butenolide production pathway, we observed no differences in the expression of Tril0 between the two isolates (Table 4) (Harris et al. 2007; McCormick et al. 2010).

In addition to analysis of common genes between the isolates, such as the Tri genes, we also examined the expression of poorly conserved genes. These genes were defined by the fact that they had an expected value greater than $1 \times 10^{-10}$, by BLASTn analysis, and were not fully transferred by RATT to the other genomes. All of the genes that were considered to be poorly conserved in either FG1 or FG2 had no reads successfully map to the coding sequence, further validating the differences in expression and lack of gene conservation of these genes between isolates. When we examined the expression of

Table 3. Genes determined to be differentially expressed by twofold or greater, $P<0.05$

\begin{tabular}{lrrr}
\hline & \multicolumn{3}{c}{ Reference genome } \\
\cline { 2 - 4 } Experimental condition & PH-1 & FG1 & FG2 \\
\hline FG1 vs. FG2 & 1,767 & 1,684 & 1,639 \\
FG1/FG2; $10: 1^{\text {a }}$ & 79 & 67 & 76 \\
FG1/FG2; $1: 1^{\text {a }}$ & 68 & 56 & 58 \\
FG1/FG2; $1: 10^{\text {a }}$ & 61 & 64 & 55 \\
\hline
\end{tabular}

a Experimental values were compared with expected values generated from the sole inoculum conditions. poorly conserved genes in the FG1 and FG2 axenic cultures, we observed that, of 147 genes that are poorly conserved in FG1 compared with FG2 (Fig. 4), 79 were differentially expressed (Supplementary Tables S4 and S6). This included 14 of the 20 genes spanning $g 3545$ to $g 3564$ on contig_207. The eight genes spanning $g 8801$ to $g 8808$ on contig_73 in FG1 were also differentially expressed. When we examined the expression patterns of the 94 FG2 genes that are poorly conserved in FG1, 40 were differentially expressed. These included $g 11499$, a putative cell wall-degrading enzyme found in $F$. oxysporum, and g6720, a putative protease also found in other Fusarium spp.

\section{Transcriptome profiling of coinoculated cultures in mycotoxin-inducing conditions.}

Since the coinoculated samples contained RNA originating from both isolates, they could not be compared directly without accounting for the abundance of each isolate in the sample. To determine the abundance of each isolate, qRT-PCR was performed with DNA extracted from the coinoculated cultures (Fig. 1C). By knowing abundance of each isolate in the sample and the expression in the pure inoculated cultures, we constructed an expected gene expression profile for each coinoculated sample; an example calculation for this is found below. The expected expression profile was then compared with the actual expression profiles of the coinoculated cultures to obtain relative expression by DESeq (Supplementary Table S3).

In contrast to axenic cultures, fewer than $1.5 \%$ of the Fusarium genes are affected in all the coinoculated culture conditions (Table 3). As with the previous analysis, we used all three isolates as a reference and found that, regardless of the reference, similar numbers of genes are differentially expressed (Table 3; Fig. 5). A detailed analysis of differentially expressed genes in various inoculum ratios between FG1 and FG2 are presented in a Venn diagram (Fig. 5). Although, there were up to eight genes common to two coinoculation conditions (FG1/FG2 ratio of 1:1 and 1:10), only two genes were differentially expressed in all three coinoculation conditions (FGSG_09051 and FGSG_16275), both of which are annotated as hypothetical proteins (Fig. 5). When the expression of these two genes was compared in the axenic cultures, FGSG_09051 had increased expression in FG1, while $F G S G \_16275$ has similar expression patterns between the isolates.

To further validate the differential expression of these genes in the coinoculated conditions, we chose four genes based on differential expression and presence or absence in the respective genome and subjected them to qRT-PCR analyses. The

Table 4. Trichothecene-associated genes have increased expression in FG2 compared with FG1 by RNA-Seq

\begin{tabular}{|c|c|c|c|c|c|c|}
\hline \multirow[b]{2}{*}{ Gene name } & \multicolumn{2}{|c|}{ PH-1 as reference } & \multicolumn{2}{|c|}{ FG1 isolate as reference } & \multicolumn{2}{|c|}{ FG2 isolate as reference } \\
\hline & Accession in PH-1 & Expression $^{\mathbf{a}}$ & Accession in FG1 & Expression $^{\mathbf{a}}$ & Accession in FG2 & Expression $^{\mathbf{a}}$ \\
\hline Tri1 & FGSG_00071 & $6.3^{\mathrm{b}}$ & $g 9888$ & $6.3^{b}$ & $g 79$ & $6.3^{\mathrm{b}}$ \\
\hline Tri8 & FGSG_03532 & $6.1^{\mathrm{b}}$ & $g 5275$ & $5.2^{\mathrm{b}}$ & $g 5383$ & $6.1^{\mathrm{b}}$ \\
\hline Tri3 & FGSG_03534 & $5.3^{\mathrm{b}}$ & $g 5276$ & $5.2^{\mathrm{b}}$ & g5584 & $5.3^{\mathrm{b}}$ \\
\hline Tri4 & FGSG_03535 & $6.2^{\mathrm{b}}$ & $g 5277$ & $6.2^{\mathrm{b}}$ & g5385 & $6.2^{\mathrm{b}}$ \\
\hline Tri6 & FGSG_16251 & $4.1^{\mathrm{b}}$ & $g 5278$ & $4.1^{\mathrm{b}}$ & g5386 & $4.1^{\mathrm{b}}$ \\
\hline Tri5 & FGSG_03537 & $6.1^{\mathrm{b}}$ & $g 5279$ & $6.1^{\mathrm{b}}$ & g5387 & $6.1^{\mathrm{b}}$ \\
\hline Trilo & FGSG_03538 & 0.2 & $g 5280$ & 0.2 & g5388 & 0.2 \\
\hline Tri9 & FGSG_03539 & $9.0^{\mathrm{b}}$ & $N P^{c}$ & - & $\mathrm{NP}^{\mathrm{c}}$ & - \\
\hline Tril1 & FGSG_03540 & $5.1^{\mathrm{b}}$ & g5281 & $5.1^{\mathrm{b}}$ & $g 5389^{d}$ & $5.2^{\mathrm{b}}$ \\
\hline Tri12 & FGSG_03541 & $5.5^{\mathrm{b}}$ & $g 5282$ & $5.3^{\mathrm{b}}$ & $g 5389^{\mathrm{d}}$ & $5.2^{\mathrm{b}}$ \\
\hline Tril4 & $F G S G \_03543$ & $6.2^{\mathrm{b}}$ & g5283 & $6.2^{\mathrm{b}}$ & g5391 & $6.2^{\mathrm{b}}$ \\
\hline Trilo1 & FGSG_07896 & $5.0^{\mathrm{b}}$ & g10380 & $5.0^{\mathrm{b}}$ & g10702 & $5.0^{\mathrm{b}}$ \\
\hline GAPDH & $F G S G \_16627$ & 0.2 & $g 7821$ & 0.2 & $g 8232$ & 0.2 \\
\hline$B-T u b$ & FGSG_09530 & 0.1 & g10789 & 0.1 & $g 11116$ & 0.1 \\
\hline
\end{tabular}

${ }^{a}$ Expression in FG2 compared with FG1 $\left(\log _{2}\right)$.

b Statistically significant by DESeq $P<0.05$.

c $\mathrm{NP}=$ genes that were not predicted by AUGUSTUS.

d The coding region of Tri11 and Tri12 spanned a single predicted gene in the FG2 isolate, i.e., g5389. 
results showed the RQ values obtained from qRT-PCR analysis for all four genes were in agreement with the expression pattern from the RNA-Seq analyses. This included genes common to both isolates (FGSG_09051 and FGSG_13870) and the genes that were poorly conserved in FG1 $\left(F G S G \_04587\right)$ or poorly conserved in FG2 (FGSG_04760) (Fig. 6).
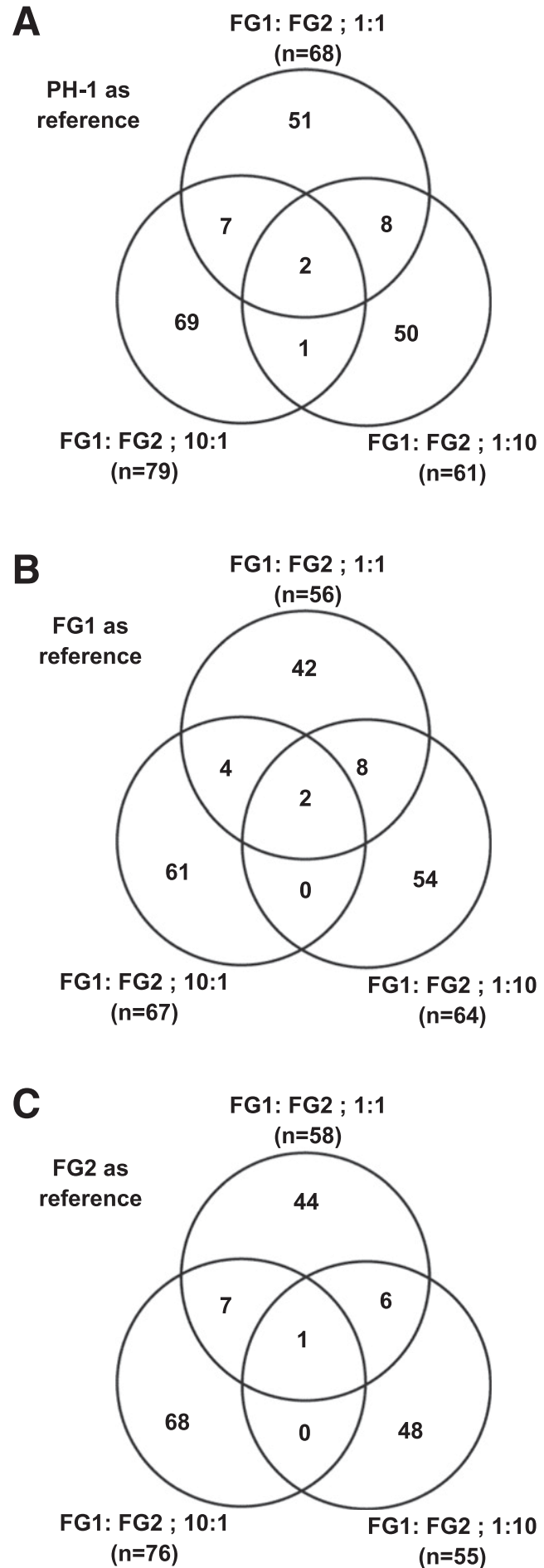

Fig. 5. Venn diagrams of differentially expressed genes in coinoculated cultures. A, PH-1 coding sequences were used as a reference. B, FG1 coding sequences were used as a reference. $\mathbf{C}, \mathrm{FG} 2$ coding sequences were used as a reference. $n$ represents the total number of differentially expressed genes in each condition. All genes are differentially expressed by DESeq, either up or down, by twofold or greater, $P<0.05$.
In contrast to the gene expression profiles observed between isolates, RNA-Seq from the coinoculated conditions suggested a downregulation trend with respect to the Tri genes. We observed a consistent pattern of downregulation, particularly in the cultures in which FG1 was dominant (10:1) (Fig. 7A). We investigated this further with qRT-PCR analysis of the Tri6 and Tri5 genes. Since the genome analysis showed polymorphism in the Tri5 gene, we designed isolate-specific primers for Tri5. As indicated, using isolate-specific primers, cultures in which the FG1 is dominant (10:1), Tri5 is significantly downregulated (Fig. 7B). Although showing a trend of downregulation, expression of Tri6 or Tri5 in other coinoculated cultures did not surpass the twofold cutoff for differential expression (Fig. 7A).

In addition to common genes, poorly conserved genes were also analyzed in the coinoculated cultures during mycotoxininducing conditions. Of 94 genes that are poorly conserved in FG1 compared with FG2 (Fig. 4), only five genes were differentially expressed including FG2-g3652, FG2-g6457, and $F G 2-g 6458$, which were downregulated when the dominant isolate was FG1, and FG2-g3377 and FG2-g3776, which were upregulated when FG2 was the dominant isolate in the inoculum. Gene g3652 corresponds to FGSG_13464 and is

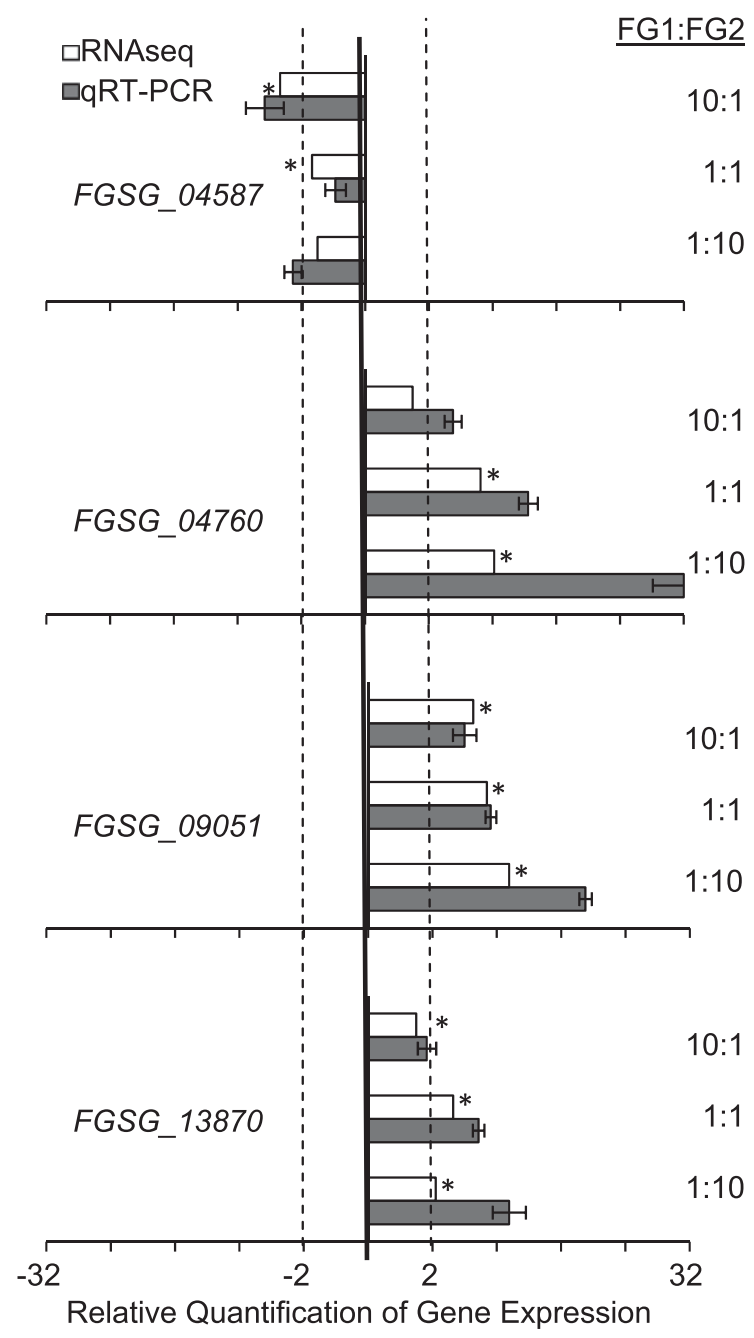

Fig. 6. Genes were determined to be differentially expressed in response to isolate interaction by both RNA-Seq and quantitative real-time polymerase chain reaction (qRT-PCR). FGSG 04587 was found to be downregulated, while $F G S G \_04760, F G S G \_09051$, and $F G S G \_013870$ were upregulated as measured by RNA-Seq (white) and qRT-PCR (gray). Data were compared with expected values based on sole inoculated cultures. Asterisks denote a significance of $P<0.05$ by DESeq 
annotated as a conserved hypothetical protein. The region harboring g6457 spans FGSG_12224 and FGSG_16089 in the $\mathrm{PH}-1$ genome, both of which are also annotated as hypothetical proteins. Gene FGSG_16089 is predicted to contain ankyrin repeat and a peptidase domain. Gene g6458, or FGSG_04587, was also affected when FG1 was dominant in the inoculum; FGSG_04587 is annotated as a related-to-WD40 repeat protein (notchless protein) and may be involved in cell signaling (Royet et al. 1998). The expression of FGSG_04587 was confirmed by qRT-PCR (Fig. 6). Gene g3377, which was upregulated when FG2 was dominant in the inoculum, has several predicted domains, including chaperonin-like, polyketide synthase, and alcohol dehydrogenase domains. Gene $g 3776$ was also upregulated and spans the hypothetical protein $F G S G \_08113$.

When we examined the expression patterns of FG1 genes that are poorly conserved in FG2, we observed that, of 147 genes, seven were differentially expressed, some of which were affected in multiple conditions and have homologs present in the PH-1 genome (Fig. 5). FG1-g6566, FG1-g11391, FG1-g11801, FG1g3555, FG1-g6521, FG1-g6650, and FG1-g8805 were all upregulated in the condition in which the ratio of FG1/FG2 was $1: 10 ; F G 1$-g6566, or FGSG_04760, was also upregulated in the 1:1 ratio and the expression was confirmed by RT-qPCR (Fig. 6). FGSG_04760 is annotated as a hypothetical secreted protein. Genes $g 11391, g 3555$, and $g 6521$ were annotated to be similar to genes from $F$. oxysporum; the protein encoded by $g 6521$ is predicted to have a fungal-specific transcription factor domain and $g 11801$ is predicted to encode for an aspartic protease. The genes $g 8805$, which is part of the gene cluster in contig_73 of the FG1 genome, and $g 6650$ encode for proteins with ankyrin repeat domains. Proteins with ankyrin repeat domains are involved in protein-protein interactions and some have been demonstrated to act as pathogen effectors (Al-Khodor et al. 2010; Pan et al. 2008).

\section{DISCUSSION}

Several studies have indicated that microbial communities can be diverse in a given geographic area, including within a single genus such as Fusarium (Boutigny et al. 2011; Lee et al. 2009; Ward et al. 2008). Undoubtedly, selective pressures have led the fungi to adapt to these communities. Fusarium isolates have been reported to produce different toxins and infect hosts with different levels of aggressiveness, indicating that isolates can be diverse, each with its own unique characteristics (O'Donnell et al. 2000; Starkey et al. 2007). In North America, at least two distinct genetic populations of the fungus have been identified, which largely separate into two trichothecene chemotypes, 3-ADON and 15-ADON (Liang et al. 2014). Emerging isolates of $15-\mathrm{ADON}$ and 3-ADON chemotypes may be of particular concern because of their increased aggressiveness in wheat (Foroud et al. 2012; Ward et al. 2008). Of particular interest to Canadian agriculture is the possibility of an increased prevalence of 3-ADON-producing isolates in regions where 15-ADON isolates normally reside (Ward et al. 2008). Several studies that have investigated pathology differences between 15-ADON- and 3-ADON-producing isolates suggest that, on average, 3-ADON isolates are more aggressive than the 15ADON isolates (Foroud et al. 2012; Gilbert et al. 2014; Puri and Zhong 2010; Ward et al. 2008). Our data supports these previous studies and showed that isolate DAOM241165 (FG1), which produces 3-ADON, caused more disease than the DAOM233423 (FG2) isolate, which produces $15-\mathrm{ADON}$ (Fig. 2). Moreover, wheat heads coinoculated with equal ratios of FG1 and FG2 resulted in disease dominated by FG1.

Comparative genomics has already provided us with insights into the dynamics of fungal evolution, thus refining our concept of 'core' versus 'flexible' genomes. The core genome is defined by genes that are commonly found in all individuals of a species. In contrast, the flexible genome tends to diversify in order to avoid host recognition or acquire new infection strategies (Baltrus et al. 2011). Several studies indicate that genes encoded in the flexible genome can be acquired by recombination and horizontal gene transfer events, even in filamentous fungi such as Fusarium spp. (Baltrus et al. 2011; Gardiner et al. 2012; $\mathrm{Ma}$ et al. 2010). Evolution of the flexible genome provides pathogens with the capacity to increase their diversity in an ongoing evolutionary tug of war between pathogen and host.

In this study, a comparison of three Fusarium isolates show approximately $97 \%$ alignment between them (Table 2). In order
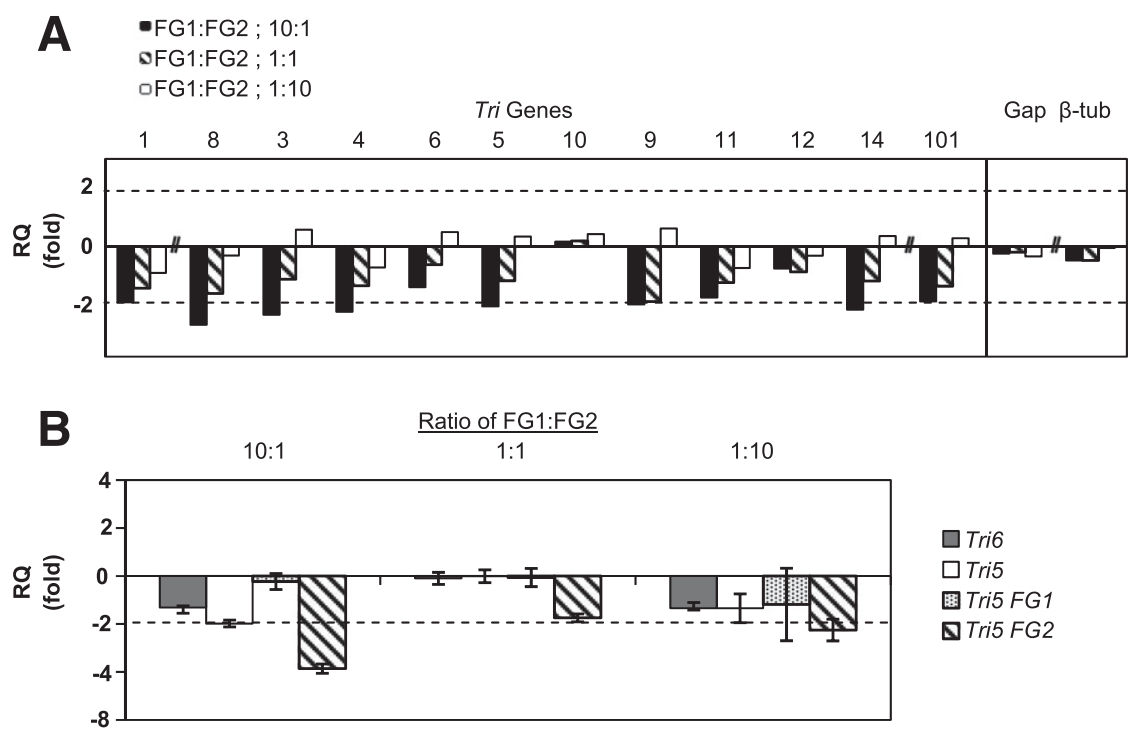

Fig. 7. Trichothecene genes show a trend toward downregulation in response to isolate interaction. A, Analyses of Tri gene expression by RNA-Seq using PH-1 coding sequences as a reference; data were normalized by DESeq and compared with expected values. The genes encoding for GAPDH (Gap) and $\beta$-tubulin ( $\beta$-tub), which were included as control genes, are highly expressed but unaffected by interference between isolates. B, Analyses of Tri6 and Tri5 gene expression by common gene sequences and Tri5 by isolate-specific gene expression by quantitative real-time polymerase chain reaction; data were compared with expected values based on sole inoculated cultures. 
to understand the flexible genome, analyses were performed with BLAST and RATT software. Genes from one genome that could not be transferred to either of two other genomes were defined as poorly conserved and those that could not be transferred to both genomes were considered as unique genes. This definition identified 62 to 148 poorly conserved genes between the three isolates and 33 to 121 unique genes in isolates (Fig. 4). Generally, these genes are located at the ends of chromosomes and in select regions within chromosomes, in which there is a greater density of SNPs and indels (Fig. 3). Approximately one third of the genes we identified in these regions that are different between genomes are annotated to be similar to genes from other Fusarium spp., suggesting that these genes may have been lost in some isolates, acquired by horizontal gene transfer events, or have simply diverged in the isolates over time. These regions likely experience higher recombination and horizontal gene transfer rates, thereby causing increased gene turnover, characteristic of flexible genomic regions. Diversity in these regions has been reported previously and genes within these regions have greater expression during infection of wheat, thus correlating regions of nucleotide variability with the flexible genome and pathology (Cuomo et al. 2007; Gardiner et al. 2012; Lysøe et al. 2011). Together, these genes are good candidates for future study of either virulence, adaptation, or both to specific environments or hosts.

In addition to the differences in gene content, transcript levels also differed between isolates when grown in vitro. RNASeq analyses showed striking differences in gene expression between FG1 and FG2 (Table 3). More than 1,500 genes, representing more than $13 \%$ of $F$. graminearum genes were differentially expressed between the two isolates. Although these two isolates are very similar (approximately 97\%) at the genome level, the expression pattern suggests that these isolates are distinct and adapt differently to the provided conditions. For instance, all of the essential genes involved in trichothecene production except for Tril0 were upregulated in FG2 compared with FG1 (Table 4). This profile was consistent regardless of which genome was used as reference, thus confirming the distinctiveness of the two isolates. The differences in gene expression profiles of the two regulatory genes Tri6 and Tri10, which positively regulate production of DON, suggests that expression of Tri genes is more closely linked to the activation of Tri6.

In addition to behaving differently, we report the outcomes of isolate interactions both in planta and in vitro. Overall, our observations indicate that interactions are inhibitory and result in reductions in infection and toxin accumulation in planta, particularly when in a FG1/FG2 ratio of $1: 10$. In vitro, we also observed interference between isolates with respect to toxin production; when in equal ratios, the 3-ADON level dropped to approximately $11 \mu \mathrm{g}$ from approximately $285 \mu \mathrm{g}$ produced by the pure inoculum (approximately 95\% drop), whereas, in the same coculture, the level of 15-ADON was reduced only from 665 to $370 \mu \mathrm{g}$ (approximately 45\% drop) (Fig. 1). This observation is mirrored in the expression profile of Tri genes, in which many of the structural genes were downregulated (Fig. 6). Despite the large differences in gene expression profiles between the isolates (Table 3), we found relatively few gene candidates that are affected by isolate interference. Although not all of these are well characterized, some are predicted to have domains previously associated with pathogen effectors, such as protease and ankyrin-repeat domains (Al-Khodor et al. 2010; Pan et al. 2008). Targeted disruptions of these genes would determine if they have a role in either intraspecies interference or plant-pathogen interaction. Together, our results provide insights into the intraspecies interactions that occur at the molecular level between distinct $F$. graminearum isolates and their consequences on toxin production and pathology in wheat.

\section{MATERIALS AND METHODS}

\section{Fungal strains and inoculum preparation.}

Two $F$. graminearum isolates were used in this study a 3ADON-producing isolate (DAOM241165, NRRL37440) from Manitoba (Canada), which we refer to as FG1, and a 15-ADONproducing isolate (DAOM233423, GZ3639, NRRL29169) from Kansas (United States), which we refer to as FG2. Macroconidia were used as the inoculum for all experiments and were produced in a liquid carboxymethylcellulose medium (Schreiber et al. 2011).

\section{Trichothecene production and identification in vitro.}

Trichothecene production of FG1 and FG2 was assessed in triplicate by modifying the two-stage media method (Nasmith et al. 2011). A nylon net filter was added to the culture plates. This allowed for even growth and avoided mycelia clumps. The culture conditions included spores from each isolate inoculated individually or in combinations of the two isolates (in ratios of $10: 1,1: 1$, or 1:10), or dilutions of the isolates with medium (in ratios of $10: 1,1: 1$, or 1:10). After $24 \mathrm{~h}$ in the glucose yeast-extract peptone (GYEP) medium, the mycelia that remained adhered to the nylon filter, which was washed several times with water, before adding second-stage media amended with putrescine at $1 \mathrm{~g}$ per liter as a sole nitrogen source (Nasmith et al. 2011). After incubating for an additional $48 \mathrm{~h}$ under the same conditions, the supernatant of the culture was removed to quantify trichothecenes. Trichothecene accumulation in the supernatant was quantified with an isocratic gradient containing $15 \%$ methanol and purified chemical standards by high-performance liquid chromatography (HPLC) (Nasmith et al. 2011).

Identification of trichothecenes was performed by nuclear magnetic resonance (NMR) from cultures as indicated previously, except the cultures were incubated with a surface-sterilized wheat head in the second-stage medium (Savard and Blackwell 1994). The culture filtrate was harvested after 6 days, was filtered by Whatman No.1 paper, was suspended on $100 \mathrm{ml}$ of ClinElute columns (Varian), was extracted with three volumes of ethyl acetate, and the extract was taken to dryness. The residues were then suspended in $0.5 \mathrm{ml}$ of $\mathrm{CDCl}_{3}$ for ${ }^{1} \mathrm{H} \mathrm{NMR}$ analysis (Savard and Blackwell 1994). NMR spectra were acquired at $500.13 \mathrm{MHz}$ on a Bruker AVANCE500 NMR spectrometer (Bruker) equipped with a TopSpin 1.3 data system.

\section{Growth assays.}

Growth was assessed in a liquid minimal medium and potato dextrose broth by inoculating 800 spores in a 96-well plate containing $200 \mu \mathrm{l}$ of medium (Leslie and Summerell 2006; Walkowiak and Subramaniam 2014). The plate was incubated at $28^{\circ} \mathrm{C}$ and optical density measurements were taken at a wavelength of $620 \mathrm{~nm}$, using a POLARstar OPTIMA plate reader (BMG LabTech); the data were analyzed using FLUOstar OPTIMA 1.32 software (BMG LabTech). Growth was also assessed on a solid minimal medium and potato dextrose agar in $8.5-\mathrm{cm}$ diameter petri dishes, using 20,000 spores inoculated onto sterile $0.6-\mathrm{cm}$ diameter filter paper disks placed in the center of dish. All cultures were grown in triplicate using the same spore combinations as before and incubated at $28^{\circ} \mathrm{C}$ in darkness.

\section{Pathology testing in wheat and PCR and qRT-PCR analyses of isolates at the endpoint of infection.}

The wheat cultivar Roblin was grown under controlled environmental conditions in growth chambers until midanthesis as described previously (Schreiber et al. 2011). The plants were point-inoculated between the palea and the lemma with a total 
of 1,000 macroconidia from either FG1 or FG2, combinations of the two isolates (in ratios of 10:1, 1:1, or 1:10), or dilutions of the isolates in water to decrease the inoculum (in ratios of 10:1, $1: 1$, or $1: 10$ ). Inoculated plants were then returned to growth chambers and were grown with regular misting for 2 days. This was repeated as three independent trials for the combinations with water and four independent trials for the combinations with both isolates. The results from all seven trials were pooled for comparative analyses. Wheat heads inoculated with FG1, FG2, or a combination thereof in ratios of $10: 1,1: 1$, or $1: 10$ were examined $21 \mathrm{dpi}$.

To ascertain the presence of an isolate in individual wheat heads at $21 \mathrm{dpi}, 10$ wheat heads for each condition were individually ground in liquid $\mathrm{N}_{2}$ and DNA was extracted, using an E.Z.N.A. Fungal DNA extraction kit (Omega). To test for the presence or absence of the isolates in the wheat samples, $100 \mathrm{ng}$ of DNA was used in a 40-cycle PCR reaction using primers specific to both FG1 ( $g 6419$ F/R) and FG2 ( $g 6823$ F/R) isolates. Similarly, to determine the amount of DON and the relative abundance of the isolates across a greater sample set, 32 wheat heads from each condition divided evenly across the seven trials were also ground in liquid $\mathrm{N}_{2}$. To determine the relative abundance of the isolates in the samples, DNA was isolated from the tissues as before and qRT-PCR analyses were performed (Walkowiak and Subramaniam 2014). Primer g6419 qPCRF/R was used to quantify FG1 and primer $g 6823$ qPCRF/R to quantify FG2; Tri6, a gene common to both isolates, was used as an internal control (Walkowiak and Subramaniam 2014). A complete list of primers used can be found in Supplementary Table S7. The amount of DON in the tissues was also quantified by enzyme-linked immunosorbent assay (Sinha et al. 1995).

\section{Genome sequencing, assembly, alignment, and gene prediction.}

Both FG1 and FG2 were sequenced according to the manufacturer's instructions using 40-bp reads from both mate-paired and paired-end libraries, by Illumina GAII sequencing. The sequencing reactions were performed by the Center for the Analysis of Genome Evolution and Function (CAGEF) at the University of Toronto, Canada. Reads were then imported into CLC Genomics Workbench 6.0.1. Prior to assembly, reads were trimmed using default trimming parameters. Short reads $<20 \mathrm{bp}$ and overrepresented sequencing anomalies were also removed. Reads were then assembled using reference based assembly and de novo assembly approaches. The de novo assembly was optimized for contig size. Low-coverage contigs and contigs shorter than $200 \mathrm{bp}$ were removed. Contigs were then reordered according to the available sequence for isolate $\mathrm{PH}-1$ from the MIPS database v3.2 using ABACAS (Assefa et al. 2009). The ordered contigs were then used along with the sequence for PH-1 in separate whole-genome alignments, using MUMMER and the default parameters of the 1-to-1 algorithm in dnadiff, which was used to extrapolate the dotplot and SNP data (Delcher et al. 1999). New genes were also predicted by AUGUSTUS and transferred between genomes by RATT (Otto et al. 2011; Stanke et al. 2004). Many of these tools are combined in the postanalysis genome improvement toolkit (Swain et al. 2012). All novel features were annotated by Blast-2-GO.

\section{RNA isolation and RNA sequencing.}

Liquid cultures were prepared in five independent biological replicates for toxin induction as before for FG1 and FG2, both as sole isolation and in combinations of 10:1, 1:1, and 1:10. After $6 \mathrm{~h}$ of incubation in the second-stage medium, mycelia were harvested and flash frozen. RNA was isolated by Trizol (Life Technologies) and was further purified by the Invitrap (Invitek). RNA sequencing was performed according to manufacturer's instructions using 145-bp reads from paired-end libraries by Illumina Miseq sequencing. The sequencing reactions were performed by CAGEF. Reads were then imported into CLC Genomics Workbench 6.0.1 and were trimmed using the same method as the genome sequencing. Reads were mapped to the coding sequences of PH-1, FG1, and FG2 genomes with the RNA-Seq Analysis tool in CLC Genomics Workbench.

\section{Normalization, validation, and analysis of RNA sequencing data.}

In order to identify genes that are differentially expressed in response to interactions between isolates in the coinoculated cultures, we constructed an expected expression profile dataset for the coinoculated samples. The expected dataset was constructed by combining read data from each biological replicate of the pure cultures. The contribution of each isolate to the expected dataset was determined by the abundance of each isolate present in the coinoculated cultures by qRT-PCR of DNA isolated from each culture. qRT-PCR was performed on DNA with isolate-specific primers as previously mentioned.

An example of the expected read counts for the gene TrilO in the coinoculated sample of the $10: 1 \mathrm{FG} 1 / \mathrm{FG} 2$ ratio is calculated as follows: $\mathrm{A}=\mathrm{B}+\mathrm{C}$, where $\mathrm{A}$ is the expected number of Tri10 reads in coinoculated culture, $\mathrm{B}$ is the expected number of Tri10 reads from FG1 in pure culture, and $\mathrm{C}$ is the expected number of Tri10 reads from FG2 in pure culture; B and C are determined by the number of TrilO reads in pure culture divided by the total reads in pure culture, multiplied by the abundance of the isolate in the sample determined by qRT-PCR, multiplied by the total reads in coinoculated sample.

Therefore, expected read counts for gene Tril0 in the coinoculated sample is equal to: $(622 / 3,805,928 \times 0.94 \times 4,680,464)+$ $(884 / 3,815,592 \times 0.06 \times 4,680,464)=784$. This was calculated for all the genes in the coinoculated sample. The read count data for the expected and actual data sets were normalized and compared in ' $\mathrm{R}$ ' by DESeq, which is part of the Bioconductor package (Anders and Huber 2010).

To confirm the differential expression of select genes when comparing FG1 and FG2 or the coinoculated samples to the expected datasets, qRT-PCR analyses were performed using transcript-specific primers for differentially expressed genes (Walkowiak and Subramaniam 2014). Isolate-specific primers were also used based on SNPs for the gene Tri5.

\section{ACKNOWLEDGMENTS}

We acknowledge technical assistance from S. Buffam and M. Zid on this project.

\section{LITERATURE CITED}

Al-Khodor, S., Price, C. T., Kalia, A., and Abu Kwaik, Y. 2010. Functional diversity of ankyrin repeats in microbial proteins. Trends Microbiol. 18: 132-139.

Alexander, N. J., McCormick, S. P., Waalwijk, C., van der Lee, T., and Proctor, R. H. 2011. The genetic basis for 3-ADON and 15-ADON trichothecene chemotypes in Fusarium. Fungal Genet. Biol. 48:485-495.

Allen, H. K., Donato, J., Wang, H. H., Cloud-Hansen, K. A., Davies, J., and Handelsman, J. 2010. Call of the wild: Antibiotic resistance genes in natural environments. Nat. Rev. Microbiol. 8:251-259.

Anders, S., and Huber, W. 2010. Differential expression analysis for sequence count data. Genome Biol. 11:R106.

Assefa, S., Keane, T. M., Otto, T. D., Newbold, C., and Berriman, M. 2009. ABACAS: Algorithm-based automatic contiguation of assembled sequences. Bioinformatics 25:1968-1969.

Bai, G.-H., and Shaner, G. 1996. Variation in Fusarium graminearum and cultivar resistance to wheat scab. Plant Dis. 80:975-979.

Baltrus, D. A., Nishimura, M. T., Romanchuk, A., Chang, J. H., Mukhtar, M. S., Cherkis, K., Roach, J., Grant, S. R., Jones, C. D., and Dangl, J. L. 2011. Dynamic evolution of pathogenicity revealed by sequencing and 
comparative genomics of 19 Pseudomonas syringae isolates. PLoS Pathog. 7:e1002132.

Boutigny, A.-L., Ward, T. J., Van Coller, G. J., Flett, B., Lamprecht, S. C., O'Donnell, K., and Viljoen, A. 2011. Analysis of the Fusarium graminearum species complex from wheat, barley and maize in South Africa provides evidence of species-specific differences in host preference. Fungal Genet. Biol. 48:914-920.

Cuomo, C. A., Güldener, U., Xu, J.-R., Trail, F., Turgeon, B. G., Di Pietro, A., Walton, J. D., Ma, L.-J., Baker, S. E., Rep, M., Adam, G., Antoniw, J., Baldwin, T., Calvo, S., Chang, Y.-L., Decaprio, D., Gale, L. R., Gnerre, S., Goswami, R. S., Hammond-Kosack, K., Harris, L. J., Hilburn, K., Kennell, J. C., Kroken, S., Magnuson, J. K., Mannhaupt, G., Mauceli, E., Mewes, H.-W., Mitterbauer, R., Muehlbauer, G., Münsterkötter, M. Nelson, D., O’donnell, K., Ouellet, T., Qi, W., Quesneville, H., Roncero, M. I. G., Seong, K.-Y., Tetko, I. V., Urban, M., Waalwijk, C., Ward, T. J. Yao, J., Birren, B. W., and Kistler, H. C. 2007. The Fusarium graminearum genome reveals a link between localized polymorphism and pathogen specialization. Science 317:1400-1402.

Delcher, A. L., Kasif, S., Fleischmann, R. D., Peterson, J., White, O., and Salzberg, S. L. 1999. Alignment of whole genomes. Nucleic Acids Res. 27:2369-2376.

Ding, L., Xu, H., Yi, H., Yang, L., Kong, Z., Zhang, L., Xue, S., Jia, H., and Ma, Z. 2011. Resistance to hemi-biotrophic $F$. graminearum infection is associated with coordinated and ordered expression of diverse defense signaling pathways. PLoS One 6:e19008.

Doohan, F. M., Parry, D. W., Jenkinson, P., and Nicholson, P. 1998. The use of species-specific PCR-based assays to analyse Fusarium ear blight of wheat. Plant Pathol. 47:197-205.

Foroud, N. A., McCormick, S. P., MacMillan, T., Badea, A., Kendra, D. F. Ellis, B. E., and Eudes, F. 2012. Greenhouse studies reveal increased aggressiveness of emergent Canadian Fusarium graminearum chemotypes in wheat. Plant Dis. 96:1271-1279.

Gardiner, D. M., McDonald, M. C., Covarelli, L., Solomon, P. S., Rusu, A. G., Marshall, M., Kazan, K., Chakraborty, S., McDonald, B. A., and Manners, J. M. 2012. Comparative pathogenomics reveals horizontally acquired novel virulence genes in fungi infecting cereal hosts. PLoS Pathog. 8:e1002952.

Geiser, D. M., Aoki, T., Bacon, C. W., Baker, S. E., Bhattacharyya, M. K., Brandt, M. E., Brown, D. W., Burgess, L. W., Chulze, S., Coleman, J. J., Correll, J. C., Covert, S. F., Crous, P. W., Cuomo, C. A., De Hoog, G. S., Di Pietro, A., Elmer, W. H., Epstein, L., Frandsen, R. J. N., Freeman, S., Gagkaeva, T., Glenn, A. E., Gordon, T. R., Gregory, N. F., HammondKosack, K. E., Hanson, L. E., Jímenez-Gasco, Mdel. M., Kang, S., Kistler, H. C., Kuldau, G. A., Leslie, J. F., Logrieco, A., Lu, G., Lysøe, E., Ma, L.-J., McCormick, S. P., Migheli, Q., Moretti, A., Munaut, F., O’Donnell, K., Pfenning, L., Ploetz, R. C., Proctor, R. H., Rehner, S. A., Robert, V. A. R. G., Rooney, A. P., bin Salleh, B., Scandiani, M. M., Scauflaire, J., Short, D. P., Steenkamp, E., Suga, H., Summerell, B. A., Sutton, D. A., Thrane, U., Trail, F., Van Diepeningen, A., Vanetten, H. D., Viljoen, A., Waalwijk, C., Ward, T. J., Wingfield, M. J., Xu, J. R., Yang, X. B., Yli-Mattila, T., and Zhang, N. 2013. One fungus, one name: Defining the genus Fusarium in a scientifically robust way that preserves longstanding use. Phytopathology 103:400-408.

Gilbert, J., Brûlé-Babel, A., Guerrieri, A. T., Clear, R. M., Patrick, S. Slusarenko, K., and Wolfe, C. 2014. Ratio of 3-ADON and 15-ADON isolates of Fusarium graminearum recovered from wheat kernels in Manitoba from 2008 to 2012. Can. J. Plant Pathol. 36:54-63.

Glass, N. L., and Kaneko, I. 2003. Fatal attraction: Nonself recognition and heterokaryon incompatibility in filamentous fungi. Eukaryot. Cell 2:1-8.

Harris, L. J., Alexander, N. J., Saparno, A., Blackwell, B., McCormick, S. P., Desjardins, A. E., Robert, L. S., Tinker, N., Hattori, J., Piché, C., Schernthaner, J. P., Watson, R., and Ouellet, T. 2007. A novel gene cluster in Fusarium graminearum contains a gene that contributes to butenolide synthesis. Fungal Genet. Biol. 44:293-306.

Lee, J., Chang, I.-Y., Kim, H., Yun, S.-H., Leslie, J. F., and Lee, Y.-W. 2009. Genetic diversity and fitness of Fusarium graminearum populations from rice in Korea. Appl. Environ. Microbiol. 75:3289-3295.

Leslie, J., and Summerell, B. 2006:Page 11. in: The Fusarium Laboratory Manual. Blackwell Publishing, USA.

Liang, J. M., Xayamongkhon, H., Broz, K., Dong, Y., McCormick, S. P., Abramova, S., Ward, T. J., Ma, Z. H., and Kistler, H. C. 2014. Temporal dynamics and population genetic structure of Fusarium graminearum in the upper midwestern United States. Fungal Genet. Biol. 73:83-92.

Lysøe, E., Seong, K.-Y., and Kistler, H. C. 2011. The transcriptome of Fusarium graminearum during the infection of wheat. Mol. Plant Microbe Interact. 24:995-1000.
Ma, L.-J., van der Does, H. C., Borkovich, K. A., Coleman, J. J., Daboussi, M.-J., Di Pietro, A., Dufresne, M., Freitag, M., Grabherr, M., Henrissat, B., Houterman, P. M., Kang, S., Shim, W.-B., Woloshuk, C., Xie, X., Xu, J.-R., Antoniw, J., Baker, S. E., Bluhm, B. H., Breakspear, A., Brown, D. W., Butchko, R. A. E., Chapman, S., Coulson, R., Coutinho, P. M. Danchin, E. G. J., Diener, A., Gale, L. R., Gardiner, D. M., Goff, S. Hammond-Kosack, K. E., Hilburn, K., Hua-Van, A., Jonkers, W., Kazan, K., Kodira, C. D., Koehrsen, M., Kumar, L., Lee, Y.-H., Li, L., Manners, J. M., Miranda-Saavedra, D., Mukherjee, M., Park, G., Park, J., Park, S.-Y., Proctor, R. H., Regev, A., Ruiz-Roldan, M. C., Sain, D., Sakthikumar, S., Sykes, S., Schwartz, D. C., Turgeon, B. G., Wapinski, I., Yoder, O., Young, S., Zeng, Q., Zhou, S., Galagan, J., Cuomo, C. A., Kistler, H. C., and Rep, M. 2010. Comparative genomics reveals mobile pathogenicity chromosomes in Fusarium. Nature 464:367-373.

Makandar, R., Nalam, V. J., Lee, H., Trick, H. N., Dong, Y., and Shah, J. 2012. Salicylic acid regulates basal resistance to Fusarium head blight in wheat. Mol. Plant Microbe Interact. 25:431-439.

McCormick, S. P., Alexander, N. J., and Harris, L. J. 2010. CLM1 of Fusarium graminearum encodes a longiborneol synthase required for culmorin production. Appl. Environ. Microbiol. 76:136-141.

McMullen, M., Jones, R., and Gallenberg, D. 1997. Scab of wheat and barley: A re-emerging disease of devastating impact. Plant Dis. 81: 1340-1348

Nasmith, C. G., Walkowiak, S., Wang, L., Leung, W. W. Y., Gong, Y., Johnston, A., Harris, L. J., Guttman, D. S., and Subramaniam, R. 2011. Tri6 is a global transcription regulator in the phytopathogen Fusarium graminearum. PLoS Pathog. 7:e1002266.

O’Donnell, K., Kistler, H. C., Tacke, B. K., and Casper, H. H. 2000. Gene genealogies reveal global phylogeographic structure and reproductive isolation among lineages of Fusarium graminearum, the fungus causing wheat scab. Proc. Natl. Acad. Sci. U.S.A. 97:7905-7910.

O’Donnell, K., Ward, T. J., Geiser, D. M., Corby Kistler, H., and Aoki, T. 2004. Genealogical concordance between the mating type locus and seven other nuclear genes supports formal recognition of nine phylogenetically distinct species within the Fusarium graminearum clade. Fungal Genet. Biol. 41:600-623.

Otto, T. D., Dillon, G. P., Degrave, W. S., and Berriman, M. 2011. RATT: Rapid annotation transfer tool. Nucleic Acids Res. 39:e57.

Pan, X., Lührmann, A., Satoh, A., Laskowski-Arce, M. A., and Roy, C. R. 2008. Ankyrin repeat proteins comprise a diverse family of bacterial type IV effectors. Science 320:1651-1654.

Picot, A., Hourcade-Marcolla, D., Barreau, C., Pinson-Gadais, L., Caron, D., Richard-Forget, F., and Lannou, C. 2012. Interactions between Fusarium verticillioides and Fusarium graminearum in maize ears and consequences for fungal development and mycotoxin accumulation. Plant Pathol. 61:140-151.

Puri, K. D., and Zhong, S. 2010. The 3ADON population of Fusarium graminearum found in North Dakota is more aggressive and produces a higher level of DON than the prevalent $15 \mathrm{ADON}$ population in spring wheat. Phytopathology 100:1007-1014.

Royet, J., Bouwmeester, T., and Cohen, S. M. 1998. Notchless encodes a novel WD40-repeat-containing protein that modulates Notch signaling activity. EMBO J. 17:7351-7360.

Savard, M. E., and Blackwell, B. A. 1994. Spectral characteristics of secondary metabolites from Fusarium fungi. Pages 59-260. in: Mycotoxins in Grain. Miller, J. D., and Trenholm, H. L., eds. Eagan Press, U.S.A.

Schreiber, K. J., Nasmith, C. G., Allard, G., Singh, J., Subramaniam, R., and Desveaux, D. 2011. Found in translation: High-throughput chemical screening in Arabidopsis thaliana identifies small molecules that reduce Fusarium head blight disease in wheat. Mol. Plant Microbe Interact. 24:640-648.

Sinha, R., Savard, M. E., and Lau, R. 1995. Production of monoclonal antibodies for the specific detection of deoxynivalenol and 15acetyldeoxynivalenol by ELISA. J. Agric. Food Chem. 43:1740-1744.

Stanke, M., Steinkamp, R., Waack, S., and Morgenstern, B. 2004. AUGUSTUS: A web server for gene finding in eukaryotes. Nucleic Acids Res. 32:W309-W312.

Starkey, D. E., Ward, T. J., Aoki, T., Gale, L. R., Kistler, H. C., Geiser, D. M., Suga, H., Tóth, B., Varga, J., and O’Donnell, K. 2007. Global molecular surveillance reveals novel Fusarium head blight species and trichothecene toxin diversity. Fungal Genet. Biol. 44:1191-1204.

Swain, M. T., Tsai, I. J., Assefa, S. A., Newbold, C., Berriman, M., and Otto, T. D. 2012. A post-assembly genome-improvement toolkit (PAGIT) to obtain annotated genomes from contigs. Nat. Protoc. 7: 1260-1284.

Von der Ohe, C., and Miedaner, T. 2011. Competitive aggressiveness in binary mixtures of Fusarium graminearum and F. culmorum isolates 
inoculated on spring wheat with highly effective resistance QTL. J. Phytopathol. 159:401-410.

Wagacha, J. M., Oerke, E.-C., Dehne, H.-W., and Steiner, U. 2012. Interactions of Fusarium species during prepenetration development. Fungal Biol. 116:836-847.

Walkowiak, S., and Subramaniam, R. 2014. A nitrogen-responsive gene affects virulence in Fusarium graminearum. Can. J. Plant Pathol. 36: 224-234.

Ward, T. J., Clear, R. M., Rooney, A. P., O’Donnell, K., Gaba, D., Patrick, S., Starkey, D. E., Gilbert, J., Geiser, D. M., and Nowicki, T. W. 2008. An adaptive evolutionary shift in Fusarium head blight pathogen populations is driving the rapid spread of more toxigenic Fusarium graminearum in North America. Fungal Genet. Biol. 45:473-484.
Windels, C. E. 2000. Economic and social impacts of Fusarium head blight: Changing farms and rural communities in the Northern Great Plains. Phytopathology 90:17-21.

Wong, P., Walter, M., Lee, W., Mannhaupt, G., Münsterkötter, M., Mewes, H.-W., Adam, G., and Güldener, U. 2011. FGDB: Revisiting the genome annotation of the plant pathogen Fusarium graminearum. Nucleic Acids Res. 39:D637-D639.

Xu, X. M., Parry, D. W., Nicholson, P., Thomsett, M. A., Simpson, D., Edwards, S. G., Cooke, B. M., Doohan, F. M., Brennan, J. M., Moretti, A., Tocco, G., Mule, G., Hornok, L., Giczey, G., and Tatnell, J. 2005. Predominance and association of pathogenic fungi causing Fusarium ear blight in wheat in four European countries. Eur. J. Plant Pathol. 112: 143-154. 